\title{
Hip and Groin Pain in Soccer Players
}

\author{
Vincenzo Candela ${ }^{1}$ Angelo De Carli ${ }^{2} \quad$ Umile Giuseppe Longo ${ }^{1}$ Sofia Sturm ${ }^{1}$ Giorgio Bruni ${ }^{2}$ \\ Giuseppe Salvatore $^{1}$ Vincenzo Denaro ${ }^{1}$
}

1 Department of Orthopaedic and Trauma Surgery, Campus Bio-

Medico University, Trigoria, Rome, Italy

2 Orthopaedic Unit and “Kirk Kilgour” Sports Injury Centre, S. Andrea Hospital, University of Rome “La Sapienza," Italy

\begin{abstract}
Address for correspondence Umile Giuseppe Longo, MD, MS, PhD, Department of Orthopaedic and Trauma Surgery, Campus Bio-Medico University, Via Alvaro del Portillo, 200, 00128 Trigoria, Rome, Italy (e-mail: g.longo@unicampus.it).
\end{abstract}

\begin{abstract}
\section{Keywords}

- groin pain

- football

- sports

- athletes

Purpose The aim of this article is to illustrate the recent framework necessary to standardize studies on groin pain and review the existing literature on groin pain in football. Methods The common pathological processes underlying groin pain such as muscle, tendon or ligament strain, bone injury or fracture, sport hernia, bursitis, osteitis pubis, and hiprelated diseases have been reviewed and current management options have been considered. Results Groin pain is considered a pain in pubic or lower abdominal or adductors region which can be monolateral or bilateral. It is common in high-intensity team sports and can negatively affect an athlete's professional carrier, causing serious disruption in the performance. Despite a high prevalence of groin pain in athletes, diagnosis and management of the underlying pathological processes remain a challenge for surgeons, radiologists, and physiotherapists alike.

Conclusion A multidisciplinary approach is essential for patients with groin pain allowing prompt diagnosis and initiation of treatment thus facilitating more rapid return to play and preventing potential long-term sequelae of chronic groin pathology.
\end{abstract}

\section{Introduction}

Football is a sport characterized by a continuous increase in athletic commitment and intensity and the pelvis and hip are subjected to considerable biomechanical stresses. ${ }^{1}$ Therefore acute and chronic groin and hip injuries are very common among soccer players. ${ }^{2}$ Unfortunately, the associated injury mechanisms remain undocumented even though information on causes of groin and hip pain are important for their prevention and therapy. ${ }^{2-4}$ The most common causes of hip and groin pain in soccer players are muscle strains. Other causes may be osteitis pubis, sports hernia, femoroacetabular impingement, bursitis, labral tears, hip dislocations, fractures, snapping hip syndrome, and many other different syndromes. ${ }^{5}$ However, the diagnosis of this disease is diffi- cult because of the complex anatomy of the area. ${ }^{6}$ The aim of this article is to illustrate the recent framework necessary to standardize studies on this pathology and review the existing literature on groin pain in football.

\section{Groin Pain}

The groin is a complex anatomical region halfway between the abdomen and the thigh. The groin area is crossed by a multitude of anatomical structures each of which, alone or in association with other adjacent structures, may be the source of groin pain in athletes. The anatomic complexity of the groin area is significant contributing factor to the vast number of terms and diagnoses reported in current literature. received

May 1, 2018

accepted

April 18, 2021

published online

June 22, 2021
DOI https://doi.org/ $10.1055 / \mathrm{s}-0041-1730978$ ISSN 2282-4324.

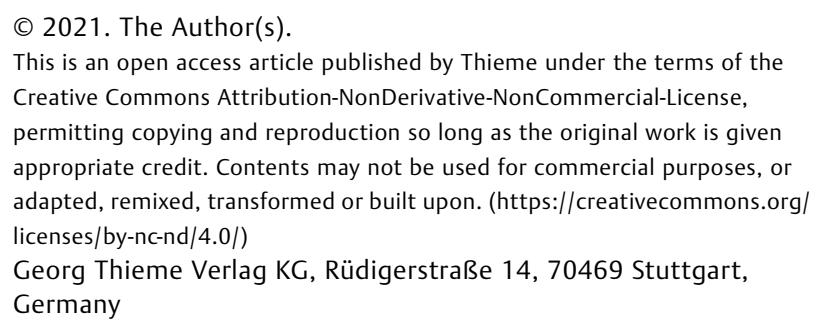


In football players, groin pain is considered a pain in pubic or lower abdominal or adductors region which can be monolateral or bilateral. In general, high running loads, sprinting, sudden change of direction, and kicking are considered potential groin injury mechanisms.

Groin injuries are common in high-intensity team sports ${ }^{7}$ and account for 8 to $18 \%$ of all injuries in soccer, ${ }^{8-16}$ with a reported incidence of 0.8 to 1.3 groin injuries per 1,000 hours of athletic activity. ${ }^{9,10,17-22}$ They can negatively affect an athlete's professional carrier, causing serious disruption in the performance of both athletic endeavors and activities of daily life. Interestingly this syndrome is rarely seen among female athletes. $^{19}$

Despite the widespread occurrence of groin pain in the soccer players, there is, still today, a lack of clearness and uniformity regarding the correct use of the terminology to classify the underlying pathologies, the diagnostic criteria and the treatment guidelines of the groin pain in athletes. At the same time, a first step in this direction has already been accomplished. In 2015, a major consensus report was published by an array of expert physician. It introduced the Doha classification system that is intended to simplify communication between medical specialists. The Doha agreement has brought significant simplification to the terminology and classification and has simplified this confusion identifying three major categories of groin pain in athletes ${ }^{23}$ mentioned below:

1. Groin pain related to a specific musculoskeletal structure.

2. Groin pain due to hip-joint disease.

3. Groin pain associated to other medical condition.

The former can further be separated into four subcategories referring to a specific anatomical region: (1a) the abdominoinguinal, (1b) the pubic, (1c) the iliopsoas, and (1d) the adductor region. ${ }^{20}$

In patients with groin pain, it is important to perform thorough physical examination to identify the exact anatomical origin of the pain. On physical examination, each region of the groin that has the potential to produce groin pain must be examined, bilaterally. This included the adductor muscles, pelvic bones, hip joint and its surrounds, the hip flexors, and the lower abdominal muscles. The physician has to identify the exact origin of the pain by palpation and consider the anatomical structure lying underneath. However, sometimes the pain may be poorly localized and felt in several different areas simultaneously. The physician must not overlook the less common but important causes of pain in this region such as intra-abdominal pathology, urinary tract pathology, gynecological pathology, and rheumatological disorders. The differential diagnosis must be made from other causes of groin pain originating from orthopaedic diseases of the spine, the pelvis, and the hip such as stress fracture, bursitis, myositis ossificans, and spinal or peripheral nerve damages.

\section{Diagnosis}

The diagnosis of hip and groin pain in soccer players is difficult because of the complex anatomic structures and the numeral and various causes. A study cohort of 34 elite young male soccer players with hip and groin pain underlines this by finding out that magnetic resonance imaging (MRI) or ultrasound findings in asymptomatic athletes are often equal to those of symptomatic athletes. Therefore these methods do not predict injury or symptom development. ${ }^{24}$ Tests that may be helpful for the diagnosis of hip and groin pain in soccer players are the isometric hip adduction (HADD-ISO) test, the isometric hip abduction (HABDISO) test, the hip flexion (HFLEXION-ISO) test, the isometric hip-flexion-modified Thomas' test (HFLEXIONMT-ISO), and the eccentric hip adduction (HADD-ECC) test. They are tested in that order and the right leg is always tested before the left leg. ${ }^{25}$ Among others, these tests can be observed that eccentric hip adduction strength is lower in soccer players with adductor-related groin pain in confront to those without. ${ }^{25}$ A cross-sectional study with male soccer players from 40 teams points out that large eccentric hip adduction strength deficits are frequently in soccer players with adductor-related groin pain in confront to asymptomatic soccer players. ${ }^{25}$ Furthermore, hip pain provocation tests, like the flexion/adduction/ internal rotation test (FADIR) and positive flexion/abduction/ external rotation tests (FABER), were also reported as helpful for the diagnosis of hip and groin pain in soccer players. Moreover investigation like plain radiographs, computed tomography (CT) scan, MR scan, bone scan, and arthroscopy are useful. ${ }^{26}$

There are also some parameters and scores which are useful for the diagnosis, like the parameter of hip range of motion (HROM) and the Copenhagen Hip and Groin Outcome Score (HAGOS). HROM is related to both hip and groin pain and also to the presence of a cam deformity (CD). ${ }^{27}$ It is measured with the hips and knees in 90 degrees of flexion and the player has to be supine. The HAGOS is lower in soccer players who have hip and groin pain in confront to those without. ${ }^{28}$

\section{Muscle Strain}

Compared with other sports, soccer, as sport with a high level of physical strain on the locomotor system, is characterized by a high prevalence of injuries in the hip and groin regions. ${ }^{29}$ The most common reason for hip and groin pain in soccer players are muscle strains. ${ }^{30}$ General strain injuries of the posterior thigh account for 10 to $23 \%$ of all acute injuries. According to literature documentation, 10 to $18 \%$ of all injuries in soccer players are groin or hip related and $62 \%$ of these are adductor strains. ${ }^{30}$ Most frequently, these muscle strains in soccer players are placed in the musculotendinous junction of the adductor longus or gracilis muscle. Usually the muscle strains are in the kicking leg of soccer players. ${ }^{31}$ Typically, a strain occurs in muscles that are overstretched or torn. ${ }^{10}$ Complete avulsions of these tendons also occur but very rarely. ${ }^{30}$ Some soccer players who sustain acute muscle strains may be able to recall a specific onset of injury in confront to others who don't remember a specific instance of the injury, those often have chronic pain. Usually clinical findings include pain with palpation of the adductor longus insertion on the pubic bone and/or pain with resisted adduction. ${ }^{9}$ A study with 36 male professional soccer players, who were randomly selected and followed-up over 2 years, compares the isokinetic profile of hip abductor and adductor muscle groups between soccer players suffering from 
chronic adductor-related groin pain (ARGP), soccer players without ARGP, and healthy volunteers from general population. The result was that the imbalance between abductor and adductor muscle groups is a risk factor for adductor-related groin injury. On account of this restoring, the correct relationship between these two hip muscles is an important preventative measure that should be a primary concern of training and rehabilitation programs. ${ }^{32}$ A descriptive and prospective study with 527 professional footballers shows that football goalkeepers are prone to acute adductor and overuse hip and groin injuries, while muscle strains, in particular located in the hamstrings, are lower compared with field players. Muscle strains are typically managed nonoperatively. ${ }^{33}$ This includes physical therapy and rehabilitation, followed by an active training program. ${ }^{9}$ Should nonoperative treatment be ineffective, a surgical intervention may be necessary. The surgical treatment in this cases is a muscle tenotomy. ${ }^{30,34}$ This last-resort option is typically more used in the chronic injuries. ${ }^{30}$

\section{Sports Hernia}

The long-term efficacy of the large series of players of this type of surgery is still to be defined. The sports hernia is a weakness in the transverse fascia (posterior wall of inguinal canal) which may allow localized bulging that compresses the genitofemoral and/or ilioinguinal nerve, causing a chronic activity related pain in the groin and its surrounding structures. ${ }^{35}$

The sports hernia commonly presents a painful groin in those sports that involve kicking and twisting movements while running, particularly soccer. Typically the pain is localized at the common point of origin of the rectus abdominis muscle and the adductor longus tendon and also of the inguinal ligament. ${ }^{36}$ Clinical findings are local tenderness over the conjoined tendon, pubic tubercle, and midinguinal region, a dilated superficial inguinal ring and pain with resisted adduction. ${ }^{37}$ The conservative treatments of sports hernias are laser, acupuncture, rehabilitative exercise, and polymeric training. These treatments improve the strength, coordination, and correct imbalance of pelvic muscles. ${ }^{38}$ Unfortunately, conservative management is often unsuccessful. An open surgical hernia repair combined with an adductor longus tenotomy relieves the in 95\% of athletes. $^{39}$ As an alternative to an open surgical treatment, laparoscopic repair is an efficient method for the treatment of groin pain originating from a sports hernia. It has fast recovery and excellent long-term results. ${ }^{40}$ After 2 to 3 weeks, the majority of the patients is able to participate in the sporting activities. ${ }^{40}$ All in all laparoscopic repair offers a shorter convalescent period and better results comparing to open surgery. ${ }^{40}$ Unfortunately, there are only few studies reporting the results of sports hernia surgical treatment, open or laparoscopic. Genitsaris et al reported only a few recurrences during the follow-up $(0.76 \%) .{ }^{40}$ The long-term efficacy and on the large series of players of this type of surgery is still to be defined.

\section{Bursitis}

In the hip and groin region, there are many bursas, but the most commonly involved are the trochanter, the ischial, and the iliopectineal bursas. ${ }^{41}$ Bursitis is mostly secondary to hip diseases and only rarely primary. Predisposing factors include a broad pelvis (female soccer players), training on banked surfaces, or roads with a slope and high intensity of training. ${ }^{42}$ Bursitis is caused by a break of synovial fluid through the bursa. This can happen under pressure or via a congenital communication from the articular cavity into the bursa. ${ }^{38}$ Bursitis most commonly occurs at the greater trochanter but an "internal" variety can occur at the iliopsoas tendon. The bursa of the greater trochanter minimizes the friction between the greater trochanter and the iliotibial band which passes over the bursa. Bursal inflammation may be caused by several conditions, such as chronic micro trauma, arthritis, regional muscle dysfunction, and overuse or acute injuries. ${ }^{42}$ A typical symptom is lateral hip pain, occasionally radiating along the distal lateral thigh. It also may be associated with snapping or clicking sensation. Sometimes, point tenderness over the greater trochanter is associated with crepitus on hip flexion and extension. Other symptoms, such as pain at the extremes of hip rotation, abduction, or adduction, and pain of contraction of the hip abductors against resistance are also symptoms. Treatment for the various locations of bursitis is similar and included rest, stretching of the involved tendons, and nonsteroidal anti-inflammatory medications. Occasionally steroid injection maybe useful. ${ }^{43}$ Surgical management may be offered following failed conservative management. The surgical includes the releasing of the iliotibial band by a cruciform incision with or without debridement of the trochanteric bursa. $^{44}$

\section{Snapping Hip Syndrome}

Snapping hip syndrome is a benign condition characterized by an audible snap or click that occurs on flexion and extension of the hip and pain during physical activities. ${ }^{45}$ In general, females are more often affected. ${ }^{45}$ There are three types of snapping to distinguish the external (lateral), internal (medial), and intra-articular one. The most frequent one is the external snapping. The external type is caused by a snapping of the iliotibial band, tensor fasciae latae, or the gluteus maximus muscle snapping over the greater trochanter during a hip flexion. ${ }^{46}$ The internal type is caused by the displacement of the iliopsoas tendon over the iliopectineal eminence or the femoral head. ${ }^{47}$ The intra-articular type is commonly caused by an intra-articular hip derangement (i.e., labral tears, hip impingement, loose bodies, fracture fragments, torn pieces of labrum, and synovial chondromatosis) which can lead to an effusion that consequently produces an internal snapping. ${ }^{45}$ In case this condition is painful or causes a bursitis, the treatment involves rest, nonsteroidal anti-inflammatory medications, ice, stretching and strengthening exercises of iliotibial band, and, in some cases, steroid injections. If the conservative treatment is not successful, surgical management may be necessary. This nonconservative treatment includes open or arthroscopic surgical release of the iliotibial band. ${ }^{45}$ 


\section{Osteitis Pubis}

Osteitis pubis is caused by repetitive trauma. This injury is often seen in soccer players. It may appear as a component of the sports hernia because tensions from the adductor muscles are implicated sometimes. Symptoms during playing soccer are pain with kicking, running, jumping, or twisting. ${ }^{48}$ The risk factors typically are excessive training, muscular imbalance, and exercising on hard surfaces. ${ }^{48}$ Typical clinical findings are tenderness over pubic symphysis aggravated by pelvic compression and painful hip abduction. Should nonoperative treatment be ineffective, curettage of the pubic symphysis is a viable option. ${ }^{49}$ A retrospective study presents the results of curettage of the pubic symphysis in 23 athletes with osteitis pubis that was refractory to initial nonoperative therapies. The result shows that $61 \%$ of patients had a follow-up with no pain and full activity of the operated hip. ${ }^{49}$

This kind of simple surgical treatment frequently has a significant benefit, especially to those athletes wishing to return to play on their previous levels. After more or less 5 months, 70\% of the patients returned to full physical activity and $61 \%$ were pain free at the time of review. ${ }^{49}$ Recovery with nonoperative management can take an extended period of time, often unsatisfactory for professional athletes. ${ }^{50}$

\section{Hip Fractures}

Hip fractures are unusual injuries in soccer players. Fractures of the proximal femur as displaced intracapsular fractures are a surgical emergency. ${ }^{51}$ Most frequently, the pubic ram is involved in this type of fractures. Stress fractures of the pubic ram account for 1 to $2 \%$ of all stress fractures. Symptoms are deeply felt pain in the groin and possibly the perineum which occurs also at rest and at night. ${ }^{51}$

\section{Femoroacetabular Impingement and Cam Deformity}

Femoroacetabular impingement (FAI) is a common cause of hip and groin pain in many soccer players aged 20 to 50 years. ${ }^{52}$ Genetic and acquired causes as etiological factors have been postulated and studied but the etiology remains controversial. Some studies suggest that genetic factors may have a role in the development of FAI but there is no conclusive evidence that FAI is transmitted genetically. ${ }^{33,53}$ Risk factors for an impingement are activities with a high range of motion of the hip or an abnormal anatomic configuration of the hip. ${ }^{54}$ Structural deformities of the hip often limit the activity of soccer players. ${ }^{55}$ The cam-type femoroacetabular impingement deformity occurs frequently in young male soccer players. Some studies find out that male soccer players have a higher prevalence of radiographic cam FAI in confront to female soccer players. ${ }^{55}$ Abnormal hip morphology can limit motion which is a result of an abnormal contact between the proximal femur and the acetabular rim. This is caused by repetitive impact of the proximal portion of the femoral neck against the acetabular labrum and its adjacent cartilage. ${ }^{54}$ Two types of femoroacetabular impingement can be distinguished the cam and pincer one. ${ }^{54}$ These two types of FAI can occur as separate entities, but it has recently been shown that combined impingement occurs in the majority of cases (86\%). ${ }^{54}$ In case the chondral injury results from cam-type impingement, this is more severe than those which result from pincer type. ${ }^{56}$ Pincer-type impingement involves an abnormal morphology of the acetabulum which causes an impingement of the labrum between the femoral neck and acetabulum. The consequences of this may be crushing, degeneration, and eventual ossification of the labrum. ${ }^{56}$ Cam impingement is the result of the contact between an abnormally shaped femoral head and a normal spherical acetabulum during moving the hip in flexion and internal rotation. This abnormal contact displaces the labrum toward the capsule and the result may be an avulsion of the labrum. ${ }^{56}$ A very popular theory for the development of camtype deformities is that there is a correlation between a high volume of impact activities during adolescence and the development of cam-type deformities. ${ }^{53}$ A study with 63 soccer players (age, expressed as mean \pm standard deviation [SD], $=23.1 \pm 4.2$ years) confirmed this. The results indicate a relationship between the frequency of football practice during skeletal growth and the presence of a CD in adulthood. ${ }^{57} \mathrm{~A}$ cross-sectional study with 89 elite soccer players and 92 controls shows that the cam-type deformities are more prevalent in soccer players than in their nonathletic peers. Cam-type deformity develops during adolescence and is influenced by highimpact sports practice. ${ }^{58}$ Symptoms of FAI are hip and groin pain, limitation of ROM and snapping or clicking sensations. A crossstudy about the ethnic differences in cam deformity including 445 male soccer players found out that East Asians have a significantly lower prevalence (18.8\%; $p \leq 0.032$ ) of cam deformity in confront to white and black soccer players. Moreover, $\alpha$ angle $>78$ degrees is more prevalent in white (33.3\%) compared with black soccer players $(17.8 \% ; p=0.041)$ and it is absent in East Asian players. So there may be ethnic differences in both acetabular morphology and femoral bony. ${ }^{59}$ Furthermore a cross-sectional study in which seasonal screening data of two professional soccer clubs were used showed that decreased HROM in professional soccer players is associated with more hip- and groin-related symptoms and with previous injuries, independent of the presence of a cam deformity. ${ }^{27}$ Another study with a total of 22 asymptomatic semiprofessional soccer players (range: 18-30 years) and 22 male amateur soccer players (control group, range: 18-29 years) found out that semiprofessional players have a higher prevalence of FAI in the kicking leg compared with amateur soccer players. Conservative treatment of femoroacetabular impingement includes physical therapy and early use of nonsteroidal anti-inflammatory drugs (NSAIDs) and the use of cortisone injections is common practice for in-season athletes. As surgical management, an arthroscopic approach is very effective with relatively high rates of reported patient satisfaction. Patients with an indication for that kind of treatment are typically young and active patients with minimal arthritis and a no salvageable labral defects.

\section{Labral Tears}

Labral tears are associated most common with major trauma, such as posterior hip dislocations or breakdown of 
surrounding structures; however, underpinning mechanisms are unclear. $^{60}$ Other causes for labral tears in soccer players are FAI coupled with specific repetitive dynamic movements, hip hyper mobility, dysplasia, and degeneration. ${ }^{61}$ Symptoms of labral tears are anterior hip or groin pain, painful episodes of anterior-medial snapping or clicking, hip instability, locking or decreased internal rotation and button pain. ${ }^{61}$ The acetabular labrum is a thick rim of dense fibrous tissue which can degenerate and tear. These processes can cause a flap which can interfere with the joint and give a deep, painful clunk during a range of activities. A retrospective review was conducted of clinical records of hip and groin injuries under the care of a single-experienced sports medicine consultant. The result of this study was that the majority of hip joint pathologies was related to femoroacetabular impingement (40\%) and labral tears (33\%). ${ }^{60}$

\section{Dislocation}

A complete dislocation of the hip is uncommon in soccer players, subluxations are more frequently. ${ }^{62}$ Dislocation of the hip occurs only with a major trauma. Subluxation occurs common in adolescents with congenital hyper laxity syndrome. In primary dislocations, those occurring in the posterior direction are more frequently in confront to anterior dislocations which account for only 8 to $15 \%$ of the total number. ${ }^{62}$ Symptoms are clunking, snapping, or popping in the groin region. Usually there is hyper mobility and poor pelvic girdle muscle strength observed in the clinical examination, but the examination may also be normal. ${ }^{62}$

\section{Conclusion}

Groin pain is a complex pathology that can keep a football player away from the fields for a long period of time. It is the third type of injury among football players after muscle tears and knee sprains. Despite a high prevalence of groin pain in athletes, diagnosis and management of the underlying pathological processes remain a challenge for surgeons, radiologists, and physiotherapists alike. A multidisciplinary approach is essential for these patients allowing prompt diagnosis and initiation of treatment thus facilitating more rapid return to play and preventing potential long-term sequelae of chronic groin pathology. It is necessary to use the same criteria recently illustrated in an expert consensus conference to standardize the pathology study methods. ${ }^{23}$ The most common cause of groin pain is a muscle, tendon, or ligament strain, particularly in athletes who play sports such as hockey, soccer, and football. Less commonly, a bone injury or fracture, hernia, bursitis, osteitis pubis, hip-related diseases, kidney stones or testicle pain. The diagnosis can be difficult and always requires a thorough medical history and adequate physical examination. Diagnostic tests can be helpful but can also lead to an overtreatment if the high number of false positives is not considered. Conservative treatment is the first choice but in some cases and in certain pathologies, surgical treatment appears to be more effective than previously considered.
Conflict of Interest

None declared.

\section{References}

1 Jacoby L, Yi-Meng Y, Kocher MS. Hip problems and arthroscopy: adolescent hip as it relates to sports. Clin Sports Med 2011;30 (02):435-451

2 Serner A, Tol JL, Jomaah N, et al. Diagnosis of acute groin injuries: a prospective study of 110 athletes. Am J Sports Med 2015;43(08): 1857-1864

3 Loppini M, Longo UG, Ragucci P, Trenti N, Balzarini L, Grappiolo G. Analysis of the pelvic functional orientation in the sagittal plane: a radiographic study with EOS 2D/3D technology. J Arthroplasty 2017;32(03):1027-1032

4 Grappiolo G, Loppini M, Longo UG, Traverso F, Mazziotta G, Denaro V. Trabecular metal augments for the management of Paprosky type III defects without pelvic discontinuity. J Arthroplasty 2015;30(06):1024-1029

5 Elattar O, Choi HR, Dills VD, Busconi B. Groin injuries (athletic pubalgia) and return to play. Sports Health 2016;8(04):313-323

6 Feeley BT, Powell JW, Muller MS, Barnes RP, Warren RF, Kelly BT. Hip injuries and labral tears in the national football league. Am J Sports Med 2008;36(11):2187-2195

7 Maffey L, Emery C. What are the risk factors for groin strain injury in sport? A systematic review of the literature. Sports Med 2007; 37(10):881-894

8 Arnason A, Sigurdsson SB, Gudmundsson A, Holme I, Engebretsen L, Bahr R. Risk factors for injuries in football. Am J Sports Med 2004;32(1, suppl):5S-16S

9 Ekstrand J, Hilding J. The incidence and differential diagnosis of acute groin injuries in male soccer players. Scand J Med Sci Sports 1999;9(02):98-103

10 Hägglund $\mathrm{M}$, Waldén $\mathrm{M}$, Ekstrand J. Injuries among male and female elite football players. Scand J Med Sci Sports 2009;19(06): 819-827

11 Hägglund M, Waldén M, Ekstrand J. Injury incidence and distribution in elite football-a prospective study of the Danish and the Swedish top divisions. Scand J Med Sci Sports 2005;15(01):21-28

12 Renström P, Peterson L. Groin injuries in athletes. Br J Sports Med 1980;14(01):30-36

13 Waldén M, Hägglund M, Ekstrand J. Injuries in Swedish elite football-a prospective study on injury definitions, risk for injury and injury pattern during 2001. Scand J Med Sci Sports 2005;15 (02):118-125

14 Werner J, Hägglund M, Waldén M, Ekstrand J. UEFA injury study: a prospective study of hip and groin injuries in professional football over seven consecutive seasons. Br J Sports Med 2009;43(13): $1036-1040$

15 Eirale C, Farooq A, Smiley FA, Tol JL, Chalabi H. Epidemiology of football injuries in Asia: a prospective study in Qatar. J Sci Med Sport 2013;16(02):113-117

16 Longo UG, Lamberti A, Petrillo S, Maffulli N, Denaro V. Scaffolds in tendon tissue engineering. Stem Cells Int 2012;2012:517165

17 Engebretsen AH, Myklebust G, Holme I, Engebretsen L, Bahr R. Intrinsic risk factors for groin injuries among male soccer players: a prospective cohort study. Am J Sports Med 2010;38(10): 2051-2057

18 Hölmich P, Thorborg K, Dehlendorff C, Krogsgaard K, Gluud C. Incidence and clinical presentation of groin injuries in sub-elite male soccer. Br J Sports Med 2014;48(16):1245-1250

19 Hägglund M, Waldén M, Ekstrand J. Previous injury as a risk factor for injury in elite football: a prospective study over two consecutive seasons. Br J Sports Med 2006;40(09):767-772

20 Hawkins RD, Hulse MA, Wilkinson C, Hodson A, Gibson M. The association football medical research programme: an audit of injuries in professional football. Br J Sports Med 2001;35(01): $43-47$ 
21 Zini R, Longo UG, de Benedetto M, et al. Arthroscopic management of primary synovial chondromatosis of the hip. Arthroscopy 2013;29(03):420-426

22 Maffulli N, Longo UG, Gougoulias N, Caine D, Denaro V. Sport injuries: a review of outcomes. Br Med Bull 2011;97:47-80

23 Weir A, Brukner P, Delahunt E, et al. Doha agreement meeting on terminology and definitions in groin pain in athletes. $\mathrm{Br} \mathrm{J}$ Sports Med 2015;49(12):768-774

24 Robinson P, Grainger AJ, Hensor EM, Batt ME, O'Connor PJ. Do MRI and ultrasound of the anterior pelvis correlate with, or predict, young football players' clinical findings? A 4-year prospective study of elite academy soccer players. Br J Sports Med 2015;49 (03):176-182

25 Thorborg K, Branci S, Nielsen MP, Tang L, Nielsen MB, Hölmich P. Eccentric and isometric hip adduction strength in male soccer players with and without adductor-related groin pain: an assessor-blinded comparison. Orthop J Sports Med 2014;2(02): 2325967114521778

26 Lee SC, Endo Y, Potter HG. Imaging of groin pain: magnetic resonance and ultrasound imaging features. Sports Health 2017;9(05):428-435

27 Tak I, Glasgow P, Langhout R, Weir A, Kerkhoffs G, Agricola R. Hip range of motion is lower in professional soccer players with hip and groin symptoms or previous injuries, independent of cam deformities. Am J Sports Med 2016;44(03):682-688

28 Thorborg K, Branci S, Stensbirk F, Jensen J, Hölmich P. Copenhagen hip and groin outcome score (HAGOS) in male soccer: reference values for hip and groin injury-free players. Br J Sports Med 2014; 48(07):557-559

29 Kittel R, Dittrich M, Fleege R, Lazik D, Wick D. [Effects of soccerspecific strains on the locomotor system] (in German). Sportverletz Sportschaden 2008;22(03):164-168

30 Nicholas SJ, Tyler TF. Adductor muscle strains in sport. Sports Med 2002;32(05):339-344

31 Hägglund M, Waldén M, Ekstrand J. Risk factors for lower extremity muscle injury in professional soccer: the UEFA injury study. Am J Sports Med 2013;41(02):327-335

32 Belhaj K, Meftah S, Mahir L, Lmidmani F, Elfatimi A. Isokinetic imbalance of adductor-abductor hip muscles in professional soccer players with chronic adductor-related groin pain. Eur J Sport Sci 2016;16(08):1226-1231

33 Longo UG, Franceschetti E, Maffulli N, Denaro V. Hip arthroscopy: state of the art. Br Med Bull 2010;96:131-157

34 Maffulli N, Loppini M, Longo UG, Denaro V. Bilateral mini-invasive adductor tenotomy for the management of chronic unilateral adductor longus tendinopathy in athletes. Am J Sports Med 2012; 40(08):1880-1886

35 Cohen B, Kleinhenz D, Schiller J, Tabaddor R. Understanding athletic pubalgia: a review. R I Med J (2013) 2016;99(10): 31-35

36 Cavalli M, Bombini G, Campanelli G. Pubic inguinal pain syndrome: the so-called sports hernia. Surg Technol Int 2014; 24:189-194

37 Choi HR, Elattar O, Dills VD, Busconi B. Return to play after sports hernia surgery. Clin Sports Med 2016;35(04):621-636

38 Yuill EA, Pajaczkowski JA, Howitt SD. Conservative care of sports hernias within soccer players: a case series. J Bodyw Mov Ther 2012;16(04):540-548

39 Messaoudi N, Jans C, Pauli S, Van Riet R, Declercq G, Van Cleemput M. Surgical management of sportsman's hernia in professional soccer players. Orthopedics 2012;35(09): e1371-e1375

40 Genitsaris M, Goulimaris I, Sikas N. Laparoscopic repair of groin pain in athletes. Am J Sports Med 2004;32(05):1238-1242
41 Mosenthal W, Kim M, Holzshu R, Hanypsiak B, Athiviraham A. Common ice hockey injuries and treatment: a current concepts review. Curr Sports Med Rep 2017;16(05):357-362

42 Friedman MV, Stensby JD, Long JR, Currie SA, Hillen TJ. Beyond the greater trochanter: a pictorial review of the pelvic bursae. Clin Imaging 2017;41:37-41

43 Barratt PA, Brookes N, Newson A. Conservative treatments for greater trochanteric pain syndrome: a systematic review. $\mathrm{Br} \mathrm{J}$ Sports Med 2017;51(02):97-104

44 Haviv B, Bronak S, Thein R. [Greater trochanteric pain syndrome of the hip]. Harefuah 2014;153(02):97-100, 126

45 Musick SR, Varacallo M. Snapping hip syndrome. In: StatPearls. Treasure Island, FL: StatPearls Publishing; 2018

46 Allen WC, Cope R. Coxa saltans: the snapping hip revisited. J Am Acad Orthop Surg 1995;3(05):303-308

47 Dobbs MB, Gordon JE, Luhmann SJ, Szymanski DA, Schoenecker PL. Surgical correction of the snapping iliopsoas tendon in adolescents. J Bone Joint Surg Am 2002;84(03):420-424

48 Gomella P, Mufarrij P. Osteitis pubis: a rare cause of suprapubic pain. Rev Urol 2017;19(03):156-163

49 Radic R, Annear P. Use of pubic symphysis curettage for treatment-resistant osteitis pubis in athletes. Am J Sports Med 2008; 36(01):122-128

50 Hallén A, Ekstrand J. Return to play following muscle injuries in professional footballers. J Sports Sci 2014;32(13):1229-1236

51 Veronese N, Maggi S. Epidemiology and social costs of hip fracture. Injury 2018;49(08):1458-1460

52 Johnson AC, Shaman MA, Ryan TG. Femoroacetabular impingement in former high-level youth soccer players. Am J Sports Med 2012;40(06):1342-1346

53 Packer JD, Safran MR. The etiology of primary femoroacetabular impingement: genetics or acquired deformity? J Hip Preserv Surg 2015;2(03):249-257

54 Han J, Won SH, Kim JT, Hahn MH, Won YY. Prevalence of cam deformity with associated femoroacetabular impingement syndrome in hip joint computed tomography of asymptomatic adults. Hip Pelvis 2018;30(01):5-11

55 Kapron AL, Peters CL, Aoki SK, et al. The prevalence of radiographic findings of structural hip deformities in female collegiate athletes. Am J Sports Med 2015;43(06):1324-1330

56 Yépez AK, Abreu M, Germani B, Galia CR. Prevalence of femoroacetabular impingement morphology in asymptomatic youth soccer players: magnetic resonance imaging study with clinical correlation. Rev Bras Ortop 2017;52(Suppl 1):14-20

57 Tak I, Weir A, Langhout R, et al. The relationship between the frequency of football practice during skeletal growth and the presence of a cam deformity in adult elite football players. $\mathrm{Br} \mathrm{J}$ Sports Med 2015;49(09):630-634

58 Agricola R, Bessems JH, Ginai AZ, et al. The development of camtype deformity in adolescent and young male soccer players. Am J Sports Med 2012;40(05):1099-1106

59 Mosler AB, Crossley KM, Waarsing JH, et al. Ethnic differences in bony hip morphology in a cohort of 445 professional male soccer players. Am J Sports Med 2016;44(11):2967-2974

60 Rankin AT, Bleakley CM, Cullen M. Hip joint pathology as a leading cause of groin pain in the sporting population: a 6-year review of 894 cases. Am J Sports Med 2015;43(07):1698-1703

61 Matcuk GR Jr, Price SE, Patel DB, White EA, Cen S. Acetabular labral tear description and measures of pincer and cam-type femoroacetabular impingement and interobserver variability on $3 \mathrm{~T}$ MR arthrograms. Clin Imaging 2018;50:194-200

62 Giza E, Mithöfer K, Matthews H, Vrahas M. Hip fracture-dislocation in football: a report of two cases and review of the literature. Br J Sports Med 2004;38(04):E17 